This is a book to delight the clinician and influence the sceptic. It can be highly commended to postgraduate medical students in all clinical fields.

\section{The Natural History of Chronic Bronchitis and Emphysema}

By Charees Fletcher, Richard Peto, Cecily Tinker and Frank E. Speizer. Pp. 272, hard cover. Oxford: Oxford University Press, 1976. £9.00.

This expensive book is well worth reading. It will be of great interest to all doctors concerned with chronic bronchitis and emphysema. It is written in beautiful English and this makes it a pleasure to read for its own sake and an example to other 'would be' authors.

Although condensed into 150 pages (plus 100 pages of references and appendices) it is virtually a 'life work'. The background to the book could hardly be more 'O.K.'. Written by Professor Charles Fletcher and his colleagues, backed by the Medical Research Council, the statistics done by Sir Richard Doll, there is even a note in the 'introduction' to suggest that it is Chapters 1, 5, 6 and 7 which are the most important.

The major conclusion of the book is that although other factors may play a role, cigarette smoking was found to be the most important environmental factor in the development of chronic bronchitis and emphysema.

Smokers, bombarded with evidence that smoking is bad for their coronary arteries, their peripheral vessels and their stomachs will find nothing here to justify the tobacco smoking which is so harmful to their lungs.

Until self-inflicted illness can be charged to the patient, the National Health Service will be responsible for the treatment of chronic bronchitis and emphysema and while this is so, there is unlikely to be a better book than this to guide the NHS or 'Private' doctor.

\section{Practice, a Handbook of Primary Medical Care}

Edited by Jack Cormack, Marshall Marinker and David Morrell. Second instalment. Kluwer-Harrap, London; 1976. £6.50.

For those who have not yet been introduced to this looseleafed handbook of primary medical care, it is necessary to explain that it is being published in three instalments; subsequently up-dating sheets and possibly chapters will be appearing at regular intervals. The text is divided into four parts, on the diagnostic process, treatment, continuing care and the complaint. This latter term covers both symptoms and diseases. In primary care, wherever and by whomever it is practised, it may not always be possible to achieve a diagnosis-a point well and clearly made in the introductory chapters. This review covers the second of the three instalments, all of which belongs to the section on 'The Complaint'. There are chapters on the confused patient, fits and faints, clumsiness, weakness and palsy, numbness and pins and needles (but why not use the more generally accepted term paraesthesia?) Other chapters deal with headache and (separately and rightly so) pain in the face and pain around the eye; difficulties patients have with sleep, vision and hearing. There is a chapter on the running stuffy nose to complement those previously published on respiratory diseases and a chapter on constipation, complementing the previously issued chapter on diarrhoea, which in turn is augmented by a chapter on rectal bleeding and rectal pain. The chapter on breast lumps also covers the technique of screening and discusses the pros and cons of this aspect of medical practice. Rheumatism in general is covered in one chapter and wrist and hand problems in another (the numbering sequence suggests that other major joints will be covered in chapters to be issued with the third instalment). Lastly there is a chapter on the infertile patient.
The handbook is now beginning to take shape. Nevertheless, one may criticize the way this has been published in three instalments. Once the three have appeared, surely noone will purchase them one at a time. Why should those who invested in this worthwhile project from the beginning have to wait?

There may be many who are puzzled by the book's title; what is 'primary medical care'? This term not only encompasses general practice as it is called in Britain and Australia, and family practice, the term used in Canada and the U.S.A., but also much of what is practised by paediatricians, internists and other specialists in those countries where they see non-referred cases. It also covers much of the work done in casualty departments and emergency rooms at a hospital.

\section{Principles of Radiation Therapy}

By Thomas J. Deeley. Pp. 159 + x, illustrated, hard cover. London: The Butterworth Group, 1976. £4.95.

Radiotherapists often feel that their work is poorly understood and underestimated. Some of the blame for this may be attributable to their lack of communication, with medical, nursing, and other colleagues, with regard to its nature and the facts about the effects and problems of administering irradiation.

The author has set himself the task of filling this deficiency, aiming to enunciate principles rather than to describe detailed radiotherapy techniques.

The first thirty-six pages are introductory in nature, but not thereby to be dismissed. The chapter on Discoveries was informative and the historical survey in the chapter on Developments useful in dispelling some of the mythology surrounding the early use of irradiation. The place of chemotherapy in the management of malignant disease is given very little room, perhaps unfairly (for example, in chapter 11, there is no mention given to the success of joint irradiation and chemotherapy in children's malignancy).

The major section of the book is devoted to external beam therapy. It is always difficult to describe complex equipment and its use in words, so diagrams have been used liberally. With the book's small page size, they appear crowded and are sometimes separated by several pages from their explanatory texts.

Other chapters discuss the use of radium sources (though with little indication given for their choice) and of radioisotopes. The latter chapter this reviewer found confusing as it did not distinguish their systemic and local uses. Hospital ward staff are often uncertain as to which patients are 'radioactive', so the instructions about the excreta in all patients 'who have received an isotope' could be misinterpreted. Other short chapters on Radiation Effects, Radiobiology and Radiation Protection provide useful but brief introductions to important subjects. The last of these especially could have been expanded with profit, detailing the 'Maximum Permissible Dose' levels and the strict controls on staff at risk. This would be reassuring to staff, caring for radiotherapy patients, without specialized knowledge, and some hints about how to apply the inverse square law in the ward situation would also seem appropriate.

\section{Psychological Medicine. An introduction to Psychiatry}

By Desmond Curran, Maurice Partridge and Peter STOREY. Pp. 444, soft cover. Edinburgh, London and New York: Churchill Livingstone, 1976. £5.75.

This textbook of general psychiatry has long been respected for its clinical wisdom devoid of cant and excessive theory. Dr Storey represents the third generation of co-authors and he has, as the present active author, begun to put his own stamp on this latest edition. The style of the book remains unchanged. The content has been expanded, not so much bebecause of the effect of general up-dating but rather because 